Pengaruh Jenis Pelarut Ekstrak daun Pinus Terhadap Aktivitas Antibakteri - Aisy, dkk Jurnal Pangan dan Agroindustri Vol.10 No.1: 47-56, Jan 2022

Diterima: 30/04/2021, Direview: 30/07/2021, Diterbitkan: 31/01/2022

\title{
PENGARUH JENIS PELARUT EKSTRAK DAUN PINUS TERHADAP AKTIVITAS ANTIBAKTERI STAPHYLOCOCCUS AUREUS DAN APLIKASINYA PADA SABUN PADAT
}

\section{Effect of Solvents on Antibacterial Activity Pine Needle Extracts against Staphylococcus aureus and Application in Solid Soap}

\author{
Rifda Rihhadatu Aisy ${ }^{1 *}$, Selly Harnesa Putri ${ }^{1}$, Tri Yuliana ${ }^{2}$ \\ 1) Jurusan Teknologi Industri Pertanian, FTIP Universitas Padjadjaran \\ JI. Raya Bandung Sumedang KM 21, Jatinangor 45363 \\ 2) Jurusan Teknologi Industri Pangan, FTIP Universitas Padjadjaran \\ JI. Raya Bandung Sumedang KM 21, Jatinangor 45363 \\ *Penulis Korespondensi, email: rifda17001@mail.unpad.ac.id
}

\begin{abstract}
ABSTRAK
Daun pinus berpotensi sebagai antibakteri alami. Aktivitas antibakteri dipengaruhi oleh variasi fitokimia yang dihasilkan setiap ekstrak dengan berbagai jenis pelarut. Tujuan penelitian ini untuk mengetahui pengaruh jenis pelarut ekstrak terhadap aktivitas antibakteri Staphylococcus aureus. Daun pinus dimaserasi menggunakan pelarut air, etanol $96 \%$, dan nheksana. Uji antibakteri ekstrak dilakukan dengan metode difusi sumuran. Ekstrak beraktivitas antibakteri tertinggi diaplikasikan menjadi sabun padat dengan konsentrasi ekstrak $1 \mathrm{gram}$, 1.5 gram; dan 3 gram, selanjutnya dilakukan evaluasi karakteristik (organoleptik, pH, stabilitas busa), uji hedonik dan iritasi. Ekstrak air memiliki zona hambat tertinggi (19.39 mm) dibandingkan dengan ekstrak etanol $(11.44 \mathrm{~mm}$ ) dan ekstrak n-heksana (tidak ada). Formulasi sabun berbagai variasi konsentrasi ekstrak daun pinus sebagai bahan aktif beraktivitas antibakteri menghasilkan sabun padat yang berwarna kuning kehijauan hingga berwarna coklat tua, memiliki aroma khas sabun dengan pH berkisar 10-11, stabilitas busa sekitar 57.33 - 66\%, tidak menimbulkan iritasi serta panelis lebih menyukai sabun padat dengan penambahan 1 gram ekstrak daun pinus.
\end{abstract}

Kata kunci: Antibakteri, Daun pinus, Jenis pelarut, Sabun padat, Staphylococcus aureus.

\section{ABSTRACT}

Pine needles have potential as a natural antibacterial. Antibacterial activity is influenced by phytochemicals produced by each extract with various solvents. The purpose is to determine effect of solvents on Staphyloccous aureus. The solvents used in maceration are aqueous, ethanol 96\%, and n-hexane. Antibacterial test was carried out by a well diffusion. The highest antibacterial extract is applied to solid soap with concentration of 1 gram, 1.5 gram, and $3 \mathrm{~g}$, further evaluation on characteristics (organoleptic, $\mathrm{pH}$, foam stability), hedonic and irritation tests. Aqueous extract has the highest inhibition zone $(19.39 \mathrm{~mm})$, ethanol extract $(11.44 \mathrm{~mm})$ and $n$-hexane (no inhibition zone). Soap formulations with various concentration of pine needles extract as the active ingredient of antibacterial activity produces soap with greenish yellow to dark brown, has a distinctive aroma of soap, ph values (10 - 11), foam stability (57.33-66\%), doesn't cause irritation and panellists prefer solid soap which added 1 gram of pine needles extract.

Keywords: Antibacterial, Pine needles, Solvents, Solid soap, Staphylococcus aureus. 


\title{
PENDAHULUAN
}

Pinus merkusii Jungh. et de Vriese merupakan komoditas asli Indonesia yang menjadi salah satu unggulan Perhutani dengan keberadaannya yang melimpah dan umumnya dimanfaatkan sebagai penghasil getah, produksi kayu, dan keperluan konservasi lahan (Lateka et al., 2019). Daun pinus memiliki potensi sebagai alelopati, antimikroba, nanofiber, budidaya, dan efek larvasida (Neis et al., 2018). Daun pinus juga dianggap mengandung senyawa yang berpotensi sebagai antibakteri seperti senyawa fenolik yang berupa tanin dan senyawa lainnya seperti alkaloid, flavonoid, saponin, dan terpenoid (Cahyanti et al., 2015; Siregar dan Nugroho, 2020).

Ekstrak daun pinus dapat diaplikasikan sebagai zat antibakteri alami dengan mengolahnya menjadi ekstrak murni yang dapat dilakukan melalui metode maserasi dengan bantuan pelarut. Kepolaran pelarut mempengaruhi senyawa aktif yang terbawa keluar oleh setiap pelarut akan memberikan efek yang berbeda, salah satunya terhadap aktivitas antibakteri (Sumitriasih et al., 2019). Pembuatan ekstrak daun pinus dalam penelitian ini menggunakan pelarut antara lain air (polar), etanol 96\% (semi polar), dan n-heksana (nonpolar) untuk membandingkan pengaruhnya terhadap aktivitas antibakteri.

Antibakteri alami dari daun pinus untuk menghambat bakteri patogen seperti Staphylococcus aureus yang dapat menginfeksi hampir semua orang dengan berbagai tingkat infeksi, seperti infeksi kulit ringan (luka dan bisul) dan infeksi yang membahayakan jiwa dengan manifestasi scalded skin syndrome, pneumonia, endokarditis, meningitis, dan sepsis (Diyantika et al., 2017; Lutpiatina, 2017).

Pengaplikasian ekstrak daun pinus sebagai antibakteri alami dapat dijadikan sebagai alternatif pengganti antibakteri sintetis untuk menghambat pertumbuhan $S$. aureus pada kulit yang dapat ditambahkan terhadap sediaan sabun padat. Antibakteri pada sabun umumnya menggunakan antibakteri sintetis. Antibakteri sintetis tersebut seperti triklosan yang bersifat toksik dan karsinogenik bagi tubuh dan lingkungan (Mardiana \& Solehah, 2020; Ningsih et al., 2019). Sabun digunakan sebagai pembersih dari kuman dan bakteri untuk menghindari terjadinya infeksi pada kulit. Menurut SNI (2016), sabun mandi padat didefiniskan sebagai pembersih kulit dengan reaksi antara alkali berupa basa anorganik atau organik dengan minyak, lemak, wax, asam, rosin melalui adanya proses saponifikasi atau netralisasi tanpa mengakibatkan timbulnya iritasi pada kulit.

Berdasarkan latar belakang diatas maka penelitian ini untuk mengkaji potensi ekstrak daun pinus sebagai bahan aktif yang memiliki aktivitas antibakteri dengan tujuan menentukan jenis pelarut terbaik berdasarkan variasi tingkat kepolaran dengan mengujinya terhadap $S$. aureus dan selanjutnya ekstrak daun pinus terbaik dapat diaplikasikan sebagai zat aktif dalam sediaan sabun padat.

\section{BAHAN DAN METODE}

\section{Bahan}

Bahan utama yang dibutuhkan antara lain daun pinus (Pinus merkusii) asal desa Batulonceng, Kabupaten Bandung Barat, Provinsi Jawa Barat; pelarut etanol 96\%, n-heksana, aquades; dan biakan murni S.aureus ATCC 29213 yang bersumber dari Fakultas Farmasi, Universitas Padjadjaran. Bahan pendukung lainnya adalah $\mathrm{NaCl}$, larutan McFarland, kloramfenikol, Mueller Hilton Agar, minyak jarak, minyak kelapa, minyak zaitun, $\mathrm{NaOH}$, kloroform, pereaksi dragendorff, $\mathrm{HCl}, \mathrm{FeCl}_{3}, \mathrm{CH}_{3} \mathrm{COOH}, \mathrm{H}_{2} \mathrm{SO}_{4}$ pekat, serbuk $\mathrm{Mg}$.

\begin{abstract}
Alat
Alat pada penelitian ini yaitu bejana, rotary vacuum evaporator, waterbath, desikator, erlenmeyer, penangas air, batang pengaduk, tabung reaksi, blender, ayakan 40 mesh, neraca analitik, kertas saring, vacuum filter, hotplate, magnetic stirrer, beaker glass, spatula, hand blender, desikator, oven, autoklaf, ose, inkubator, cawan petri, crock bor, mikropipet, jangka
\end{abstract}


sorong, termometer, vortex, $\mathrm{pH}$ meter, kapas, cetakan sabun, gelas ukur, pipet ukur, laminar air flow, corong, alumunium foil.

\section{Desain Penelitian}

Perlakuan ekstraksi daun pinus ini menggunakan tiga jenis pelarut dan tiga ulangan. Analisis data keberagaman untuk mengetahui adanya pengaruh pemberian ekstrak dari berbagai pelarut terhadap aktivitas antibakteri $S$. aureus dilakukan dengan uji One Way ANOVA (analisis satu arah) dengan taraf kepercayaan 95\%. Apabila ditunjukan adanya pengaruh, selanjutnya dilakukan uji Duncan untuk mengetahui perlakuan yang memberikan pengaruh atau perbedaan nyata terhadap perlakuan yang lain.

\section{Tahapan Penelitian}

Tahapan yang dilakukan pada penelitian ini dimulai dari pembuatan ekstrak daun pinus yang dimaserasi menggunakan tiga jenis pelarut yaitu air, etanol $96 \%$, dan n-heksana. Analisis terhadap ekstrak daun pinus dilakukan untuk menghitung rendemen, skrining fitokimia, dan aktivitas antibakteri terhadap Staphylococcus aureus. Ekstrak yang memiliki aktivitas antibakteri tertinggi nantinya akan diformulasikan terhadap ketersediaan sabun padat. Pembuatan sabun padat dimulai dengan mencampurkan formula dari berbagai minyak dan variasi ekstrak. Evaluasi yang dilakukan pada karakteristik sabun padat dengan ekstrak daun pinus ialah pengujian organoleptik, $\mathrm{pH}$, stabilitas busa dan melakukan uji panelis untuk mengetahui pengujian hedonik dan iritasi. Diagram alir keseluruhan tahapan penelitian ini dapat dilihat pada Gambar 1.

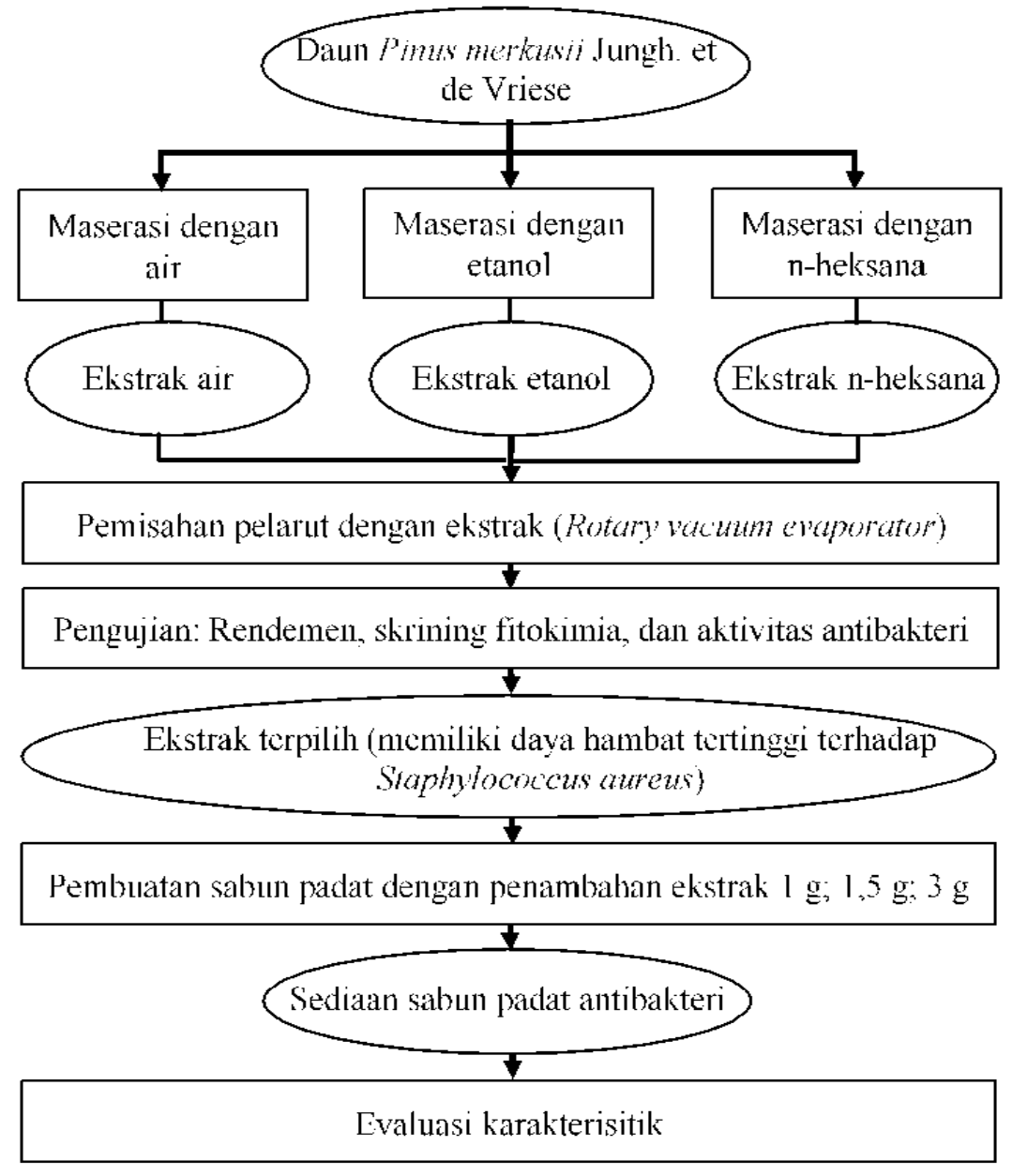

Gambar 1. Diagram Alir Tahapan Penelitian 


\section{Metode}

\section{Ekstraksi Daun Pinus}

Sampel daun Pinus merkusii yang terkumpul dicuci dengan air mengalir. Sampel yang telah bersih dapat ditiriskan dan dikeringkan angin pada suhu ruang selama 7x24 jam. Sampel yang telah kering selanjutnya diperkecil dengan bantuan blender untuk memperluas permukaan dan dilakukan pengayakan 40 mesh.

Ekstraksi dilakukan dengan maserasi. Simplisia daun pinus yang berjumlah 200 gram dimasukkan ke dalam masing-masing pelarut berbeda yaitu air, etanol $96 \%$ dan n-heksana. Maserasi dengan masing-masing pelarut dilakukan selama 3x24 jam dengan perlakuan sesekali diaduk. Ketiga maserasi ini selanjutnya disaring menggunakan vacuum filter sehingga akan menghasilkan filtrat ekstrak cair. Ekstrak cair selanjutnya dilakukan pemekatan sebagai proses pemisahan pelarut dari ekstrak dengan bantuan rotary vacuum evaporator hingga tidak ada pelarut yang menetes dan akhirnya menghasilkan ekstrak kental (Ambaro et al., 2020).

\section{Pembuatan Sediaan Sabun Padat}

Pembuatan sabun padat menggunakan metode cold process dimulai dengan perlakuan pelarutan $\mathrm{NaOH}$ yang dimasukkan ke dalam aquades. Komposisi formulasi sabun padat alami dapat dilihat pada Tabel 1. Perlakuan yang lainnya dilakukan pada wadah berbeda untuk pencampuran minyak jarak, minyak zaitun dan minyak kelapa. Larutan $\mathrm{NaOH}$ dilarutkan ke dalam campuran minyak dengan pengadukan menggunakan hand blender hingga homogen dan membentuk trace (sabun mengental). Ekstrak daun pinus terpilih dimasukkan ke dalam campuran sebelumnya pada kondisi trace dan diaduk terus-menerus hingga homogen. Sediaan sabun yang telah tercampur dalam keadaan cair dituang ke dalam cetakan sabun dan didiamkan hingga sabun mengeras kurang lebih selama 24 jam. Sabun yang telah mengeras selanjutnya didiamkan selama 4-6 minggu hingga sabun tersebut dapat digunakan (Sukawaty et al., 2016).

Tabel 1. Formula Sabun Padat

\begin{tabular}{clccc}
\hline \multirow{2}{*}{ No } & \multirow{2}{*}{ Bahan (g) } & \multicolumn{3}{c}{ Formula } \\
\cline { 3 - 5 } & & I & II & III \\
\hline 1 & Ekstrak Daun Pinus & 1 & 1.5 & 3 \\
2 & Minyak Jarak & 5 & 5 & 5 \\
3 & Minyak Zaitun & 20 & 20 & 20 \\
4 & Minyak Kelapa & 35 & 35 & 35 \\
5 & NaOH & 9.28 & 9.28 & 9.28 \\
6 & Aquades & 21.65 & 21.65 & 21.65 \\
\hline \multicolumn{2}{c}{ Sumber: Modifikasi (Cahyaningrum et al., 2020; Putri et al., 2019) }
\end{tabular}

\section{Prosedur Analisis}

\section{Prosedur Skrining Fitokimia}

Skrining fitokimia dilakukan secara kualitatif menggunakan metode tabung dan pengujian dilakukan terhadap senyawa yang berpotensi sebagai antibakteri seperti alkaloid, tanin, flavonoid, saponin, dan terpenoid.

\section{Pengujian Aktivitas Antibakteri Ekstrak}

Pengujian antibakteri pada ekstrak dilakukan menggunakan metode berupa difusi sumuran agar. MHA cair dituangkan sebanyak $15 \mathrm{ml}$ sedikit demi sedikit ke dalam cawan petri. Suspensi S. aureus diinokulasikan sebanyak $100 \mu l$ pada media cair lalu selanjutnya cawan petri digoyang pada permukaan meja membentuk angka delapan hingga homogen. Sumuran dibuat menggunakan crock bor dengan diameter $6 \mathrm{~mm}$ sebanyak 3 sumuran setelah media memadat. Masing-masing sumuran diisi oleh ekstrak dari berbagai pelarut dengan konsentrasi $100 \%$ sebanyak $30 \_\mu l$ menggunakan mikropipet. Pengujian antibakteri terhadap 
kontrol menggunakan kontrol positif kloramfenikol 1\% (positif) dan aquades steril (negatif) dilakukan pada cawan petri yang lain. Cawan petri diinkubasi menggunakan suhu $37_{-}^{\circ} \mathrm{C}$ dengan waktu 1x24 jam di dalam inkubator. Aktivitas antibakteri yang dapat diukur adalah zona hambat yang berupa area bening diukur dengan bantuan jangka sorong (Fitriyanti et al., 2019).

\section{Evaluasi Karakteristik Sabun Padat}

Pengamatan dilakukan setelah melalui proses curing selama 4 - 6 minggu dengan pengujian terhadap organoleptik (warna, aroma, tekstur), nilai $\mathrm{pH}$, dan stabilitas busa.

a. Pengujian Organoleptik

Pengamatan terhadap warna, aroma, dan tekstur sabun padat.

b. Pengujian $\mathrm{pH}$

Sampel sabun $1 \mathrm{~g}$ dilarutkan ke dalam aquades $10 \mathrm{ml}$ hingga homogen. $\mathrm{pH}$ meter dimulai dengan perlakuan kalibrasi pada larutan buffer yang berupa larutan dengan $\mathrm{pH}$ bernilai 4 dan 9. Elektroda dibersihkan dengan air bebas $\mathrm{CO}_{2}$ dan selanjutnya larutan dimasukkan elektroda dan menunggu hingga indikator $\mathrm{pH}$ menghasilkan nilai $\mathrm{pH}$ yang konstan dan stabil. Jika terdapat selisih 0,2 harus dilakukan pengulangan dimulai dari kalibrasi (SNI, 1994).

c. Pengujian Stabilitas Busa

Sediaan sabun diambil $1 \mathrm{~g}$ lalu diencerkan ke dalam $10 \mathrm{ml}$ aquades pada tabung reaksi dan dihomogenkan selama 1 menit. Busa yang dihasilkan pada waktu awal merupakan parameter tinggi busa awal yang diukur tingginya dengan penggaris dan busa yang dihasilkan setelah dihomogenkan selama 5 menit sebagai tinggi busa akhir (Fatimah \& Jamilah, 2018).

\section{Prosedur Uji Hedonik}

Pengujian terhadap kesukaan atau hedonik dilakukan terhadap 10 panelis dalam rentang usia 18-25 tahun dan bukan merupakan kelompok terlatih. Panelis terpilih akan diminta untuk mengungkapkan tanggapan terkait tingkat kesukaannya pada sediaan sabun padat yang mengandung berbagai konsentrasi ekstrak daun pinus dengan parameter fisik seperti pengamatan terhadap warna, aroma, tekstur, dan banyak busa yang dihasilkan. Penilaian diterima dalam bentuk skala 1 hingga skala 5 yang merupakan parameter penilaian sangat tidak suka hingga sangat suka (Fatimah \& Jamilah, 2018).

\section{Prosedur Uji Iritasi}

Uji iritasi dilakukan untuk melihat adanya perubahan pada kulit seperti timbulnya gatal, kemerahan, dan kasar terhadap panelis dengan cara mencuci tangan menggunakan sabun yang diuji dan diaplikasikan dengan menggosoknya selama satu menit untuk selanjutnya dibilas dan didiamkan selama lima menit (Fatimah \& Jamilah, 2018).

\section{HASIL DAN PEMBAHASAN}

\section{Rendemen Ekstrak}

Perlakuan perbedaan jenis pelarut yang dihasilkan oleh analisis ragam menghasilkan pengaruh yang sangat nyata terhadap nilai rata-rata rendemen ekstrak daun pinus. Hasil analisis perhitungan rendemen rata-rata hasil ekstrak daun pinus dapat dilihat pada Tabel 2.

\begin{tabular}{lr}
\multicolumn{2}{c}{ Tabel 2. Hasil Rendemen Ekstrak } \\
\hline Jenis Ekstrak & Rendemen (\%) \\
\hline Air & $6.43 \pm 0.35^{\mathrm{b}}$ \\
Etanol & $13.47 \pm 0.38^{\mathrm{c}}$ \\
n-Heksana & $2.44 \pm 0.21^{\mathrm{a}}$ \\
\hline
\end{tabular}

Keterangan: *a.b = notasi huruf serupa menunjukkan tidak ada perbedaan nyata pada taraf $5 \%$ menggunakan uji Duncan 
Ekstrak dengan pelarut etanol 96\% merupakan ekstrak yang menghasilkan rendemen tertinggi dengan nilai rata-rata rendemen sebesar $13.47 \%$, selanjutnya diikuti rendemen ekstrak dengan pelarut air yang menghasilkan dengan nilai rata-rata rendemen adalah $6.43 \%$

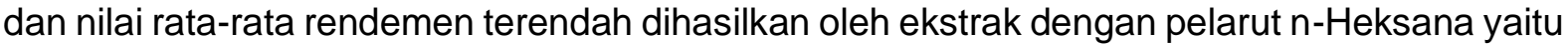
$2.28 \%$. Perbedaan nilai rendemen pada setiap penggunaan pelarut yang berbeda dapat terjadi karena setiap pelarut yang memiliki sifat kelarutan yang berbeda dalam menarik komponen bioaktif berdasarkan kesamaan polaritasnya (Verdiana et al., 2018).

\section{Skrining Fitokimia}

Identifikasi fitokimia dilakukan untuk melihat kandungan senyawa pada ekstrak daun pinus dengan melarutkan ekstrak dari masing-masing pelarut dengan pereaksi yang sesuai dengan lima jenis senyawa yang diduga memiliki aktivitas sebagai antibakteri. Senyawa fitokimia tersebut antara lain adalah alkaloid, tanin, flavonoid, saponin dan steroid/terpenoid. Hasil skrining fitokimia yang berasal dari berbagai jenis ekstrak daun pinus dapat ditinjau pada Tabel 3.

Tabel 3. Fitokimia Ekstrak Daun Pinus

\begin{tabular}{|c|c|c|c|c|c|}
\hline $\begin{array}{l}\mathbf{N} \\
\mathbf{0}\end{array}$ & $\begin{array}{c}\text { Uji } \\
\text { Fitokimia }\end{array}$ & Hasil Skrining Fitokimia & $\begin{array}{l}\text { Ekstrak } \\
\text { Air }\end{array}$ & $\begin{array}{c}\text { Ekstrak } \\
\text { Etanol }\end{array}$ & $\begin{array}{r}\text { Ekstrak n- } \\
\text { Heksana }\end{array}$ \\
\hline 1 & Alkaloid & Warna jingga atau cokelat & +++ & ++ & - \\
\hline 2 & Tanin & $\begin{array}{l}\text { Warna hijau atau biru } \\
\text { kehitaman }\end{array}$ & +++ & ++ & - \\
\hline 3 & Flavonoid & Warna merah hingga jingga & +++ & + & - \\
\hline 4 & Saponin & $\begin{array}{l}\text { Busa terbentuk } 1-10 \mathrm{~cm} \\
\text { selama } 10 \text { menit }\end{array}$ & ++ & +++ & - \\
\hline & Steroid & Warna hijau atau biru & - & - & +++ \\
\hline 5 & Terpenoid & $\begin{array}{l}\text { Warna merah, jingga atau } \\
\text { ungu }\end{array}$ & +++ & +++ & - \\
\hline
\end{tabular}

Keterangan: (+) positif = mengandung golongan senyawa (banyaknya + menunjukkan intensitas warna

$(-)$ negatif $=$ tidak mengandung golongan senyawa

Hasil pengujian terhadap ekstrak air dan ekstrak etanol daun pinus menyatakan terkandungnya alkaloid, tanin, flavonoid, saponin, dan terpenoid. Ekstrak air lebih mendominasi senyawa seperti alkaloid, tanin, flavonoid, dan terpenoid sedangkan ekstrak etanol memiliki intensitas yang dominan pada saponin dan terpenoid. Sedangkan hasil fitokimia pada ekstrak n-heksana hanya mengandung steroid. Hasil ekstrak etanol serupa seperti penelitian terdahulu yang telah diteliti oleh Ramadhani et al. (2021) yang menunjukkan hasil ekstrak etanol dari daun pinus memiliki senyawa bioaktif yaitu alkaloid, flavonoid, fenol, steroid, tanin, dan terpenoid.

\section{Aktivitas Antibakteri Ekstrak}

Analisis zona hambat ekstrak daun pinus menunjukkan bahwa ketiga jenis ekstrak dari berbagai pelarut menghasilkan sensitivitas terhadap $S$. aureus yang berbeda. Analisis data keberagaman untuk mengetahui adanya pengaruh pemberian ekstrak dari berbagai pelarut terhadap aktivitas antibakteri S. aureus dilakukan dengan uji One Way ANOVA (analisis satu arah) dengan taraf kepercayaan 95\% selanjutnya dilakukan uji Duncan. Hasil Analisa secara statistika menghasilkan rata-rata zona hambat pada ketiga ekstrak daun pinus dengan variasi pelarut menunjukan perbedaan nyata terhadap pertumbuhan $S$. aureus yang dapat dilihat pada Tabel 4.

Hasil pengujian aktivitas antibakteri pada Tabel 4 menghasilkan nilai rata-rata zona hambat berurutan dari nilai tertinggi yaitu, ekstrak air sebesar $19.39 \mathrm{~mm}$, ekstrak etanol sebesar $11.44 \mathrm{~mm}$ dan ekstrak n-heksana menunjukkan tidak menghasilkan aktivitas antibakteri. Menurut Davis \& Stout (1971), zona hambat antibakteri dikategorikan menjadi 
lemah pada diameter kurang dari $5 \mathrm{~mm}$, diameter 5 hingga $10 \mathrm{~mm}$ merupakan kategori sedang, kategori kuat pada diameter 10 hingga $20 \mathrm{~mm}$, dan diameter lebih dari $20 \mathrm{~mm}$ merupakan kategori sangat kuat sehingga ekstrak air dan etanol dari daun pinus menghasilkan aktivitas antibakteri dengan kategori kuat, namun tidak adanya aktivitas antibakteri pada ekstrak n-heksana.

Tabel 4. Hasil Zona Hambat Ekstrak

\begin{tabular}{lcc}
\hline \multicolumn{1}{c}{ Jenis Ekstrak } & Zona Hambat \pm STD $(\mathbf{m m})$ & Kategori \\
\hline Air & $19.39 \pm 1.92^{\mathrm{c}}$ & Kuat \\
Etanol $96 \%$ & $11.44 \pm 1.83^{\mathrm{a}}$ & Kuat \\
n-Heksana & 0 & Tidak ada \\
Kontrol Positif & $15.17 \pm 1.04^{\mathrm{b}}$ & Kuat \\
Kontrol Negatif & 0 & Tidak ada \\
\hline $\begin{array}{l}\text { Keterangan: }{ }^{\star} \text { a,b,c }=\text { notasi huruf serupa menunjukkan tidak ada perbedaan nyata pada taraf } \\
\text { 5\% menggunakan uji Duncan }\end{array}$
\end{tabular}

Kontrol positif berupa kloramfenikol 1\% menghasilkan zona hambat dengan nilai ratarata sekitar $15.17 \mathrm{~mm}$. Kontrol negatif yang digunakan adalah aquades steril menunjukkan bahwa air tidak menghasilkan aktivitas antibakteri. Hasil tersebut menunjukkan aktivitas antibakteri bukan berasal dari pelarut air namun dipengaruhi interaksi antara pelarut dan senyawa yang terkandung dalam ekstrak. Hal ini juga menyimpulkan ekstrak air daun pinus berpotensi dijadikan alternatif sebagai antibakteri alami karena melebihi kemampuan antibakteri antibiotik.

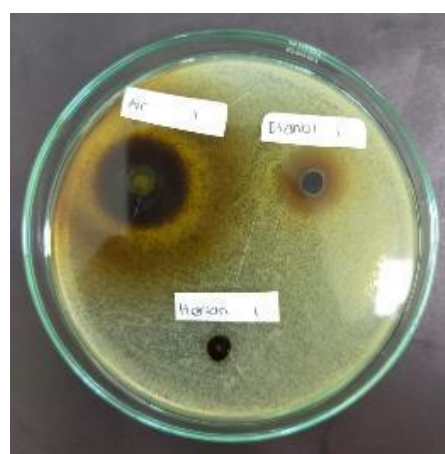

(a)

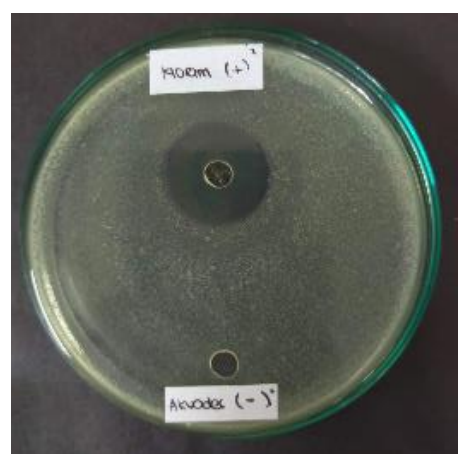

(b)

Gambar 2. (a) Antibakteri Ekstrak; (b) Antibakteri Kontrol

\section{Karakteristik Sabun Padat}

Evaluasi terhadap karakteristik sabun padat dilakukan setelah sediaan melalui proses curing selama 4-6 minggu. Curing dilakukan sebagai proses untuk menyempurnakan proses saponifikasi yang terjadi pada sabun untuk membentuk sediaan sabun yang lebih stabil (Cahyaningrum et al., 2020). Hasil evaluasi karakteristik sabun padat ekstrak daun pinus dapat ditinjau pada Tabel 5 dan penampakan fisik sediaan sabun padat dapat ditinjau pada Gambar 2.

Penambahan konsentrasi ekstrak daun pinus diformulasikan ke dalam sediaan sabun padat dengan konsentrasi 1 gram (F1), 1.5 gram (F2), dan 3 gram (F3). Uji organoleptik meliputi pengamatan terhadap warna, aroma, dan tekstur sabun padat. Warna menjadi salah satu kriteria penerimaan produk yang memiliki nilai estetika. Ekstrak air daun pinus memiliki warna coklat kehijauan. Penambahan ekstrak air daun pinus mempengaruhi warna sabun padat, semakin tinggi konsentrasi ekstrak daun pinus yang ditambahkan maka intensitas warna sabun padat akan semakin pekat. 
Tabel 5. Karakteristik Sabun Padat

\begin{tabular}{llccc}
\hline \multirow{2}{*}{ Uji } & & \multicolumn{3}{c}{ Formula Konsentrasi Ekstrak } \\
\cline { 3 - 5 } & \multirow{2}{*}{ Warna } & Kuning & F2 & F3 \\
\hline \multirow{4}{*}{ Organoleptik } & kehijauan & Kuning & kocoklatan & Coklua \\
& Aroma & Khas sabun & Khas sabun & Khas \\
& Tekstur & Padat & Padat & Padat \\
pH & & 10.46 & 10.50 & 10.68 \\
Stabilitas busa & $57.33 \%$ & $61.67 \%$ & $66.00 \%$ \\
\hline
\end{tabular}

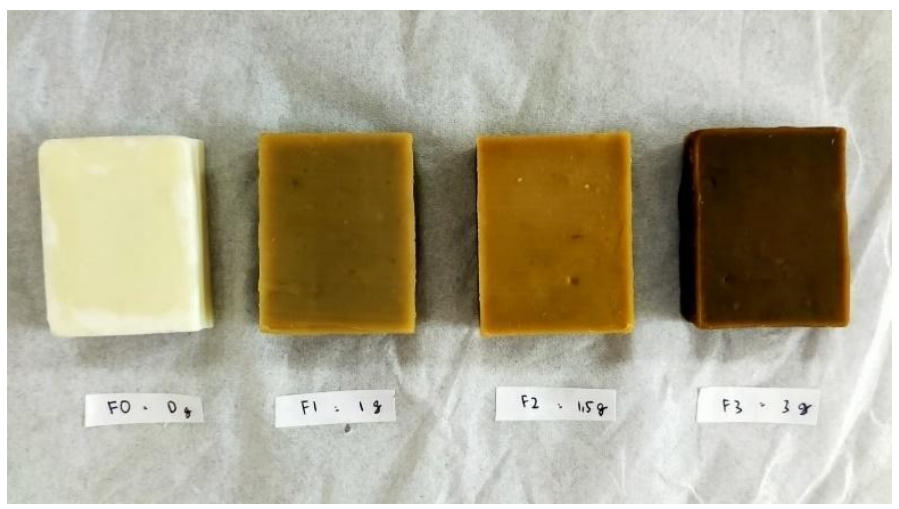

\section{Gambar 3. Penampakan Sediaan Sabun Padat}

Derajat keasaman $(\mathrm{pH})$ menunjukkan nilai $\mathrm{pH}$ pada sabun agar sesuai dengan standar sehingga diharapkan tidak mengiritasi kulit. Hasil pengujian $\mathrm{pH}$ ketiga sediaan sabun yang menggunakan ekstrak daun pinus menghasilkan rata-rata $\mathrm{pH}$ terendah 10.46 dan tertinggi 10.68 (Tabel 5). Nilai pH yang dihasilkan menyatakan bahwa sabun padat yang dihasilkan aman dan dapat digunakan mendekati rentang $\mathrm{pH}$ yang terkandung dalam sabun padat komersial seperti yang diteliti oleh Setiawati \& Ariani (2020) menyatakan bahwa sabun mandi padat di pasaran mengandung $\mathrm{pH}$ sekitar 9.99 - 10.42 dan nilai $\mathrm{pH}$ sabun antiseptik berkisar 9.99 - 10.47.

Pengujian terhadap stabilitas busa berguna untuk meninjau kestabilan sabun padat ekstrak daun pinus dalam menghasilkan busa setelah bercampur dengan air. Umumnya nilai stabilitas busa berkisar 60-70\% setelah dalam jangka waktu 5 menit (Dewi et al., 2021). Nilai rata-rata stabilitas busa pada sabun padat yang dihasilkan penelitian ini berkisar antara 57.33 $-66 \%$.

\section{Uji Hedonik}

Pengujian kesukaan panelis terhadap sediaan sabun padat ekstrak daun pinus yang dihasilkan dilakukan untuk mempertimbangkan respon penerimaan panelis. Panelis yang dipilih merupakan panelis berumur $18-25$ tahun dan merupakan kelompok tidak terlatih. Penilaian dilakukan melalui kuesioner pada panelis berdasarkan tingkat kesukaan dengan skala 1 hingga skala 5 yang merupakan parameter penilaian sangat tidak suka hingga parameter penilaian sangat suka. Pengujian hedonik terhadap 10 panelis dapat ditinjau hasil analisisnya pada Tabel 6.

Berdasarkan hasil dari uji hedonik terkait penerimaan panelis terhadap sediaan sabun padat ekstrak daun pinus dengan penambahan berbagai konsentrasi menunjukkan F1 dengan penambahan konsentrasi ekstrak daun pinus sebanyak 1 (satu) gram menjadi sediaan yang paling disukai. Hasil analisis menyatakan indikator warna dan tekstur pada sabun padat antara F1 menghasilkan perlakuan yang tidak berbeda nyata dengan F2, sedangkan perlakuan $\mathrm{F} 1$ adanya perbedaan yang nyata dengan $\mathrm{F} 3$. Analisis terhadap aroma sabun padat menyatakan tidak adanya perbedaan nyata antara formulanya. 
Tabel 6. Uji Hedonik Sediaan Sabun Padat

\begin{tabular}{lccc}
\hline \multirow{2}{*}{ Parameter } & \multicolumn{3}{c}{ Formula Konsentrasi Ekstrak } \\
\cline { 2 - 4 } & $\mathbf{F 1}$ & $\mathbf{F 2}$ & $\mathbf{F 3}$ \\
\hline Warna & $3.97^{\mathrm{b}}$ & $3.93^{\mathrm{b}}$ & $3.00^{\mathrm{a}}$ \\
Aroma & $3.73^{\mathrm{a}}$ & $3.60^{\mathrm{a}}$ & $3.47^{\mathrm{a}}$ \\
Tekstur & $4.07^{\mathrm{b}}$ & $3.83^{\mathrm{ab}}$ & $3.50^{\mathrm{a}}$ \\
\hline
\end{tabular}

Keterangan: ${ }^{*} a, b=$ notasi huruf serupa menunjukkan tidak ada perbedaan nyata pada taraf $5 \%$ menggunakan uji Duncan

\section{Uji Iritasi}

Uji iritasi dilakukan untuk mengetahui reaksi kulit terhadap penggunaan sabun padat terhadap bentuk iritasi kulit seperti gatal, kasar, dan kemerahan. Hasil pengujian terhadap iritasi penggunaan sabun padat terhadap kulit panelis dapat dilihat pada Tabel 7.

Tabel 7. Hasil Iritasi Sediaan Sabun Padat

\begin{tabular}{lcccccccccc}
\hline \multirow{2}{*}{ Formulasi } & \multicolumn{10}{c}{ Panelis } \\
\cline { 2 - 11 } & $\mathbf{1}$ & $\mathbf{2}$ & $\mathbf{3}$ & $\mathbf{4}$ & $\mathbf{5}$ & $\mathbf{6}$ & $\mathbf{7}$ & $\mathbf{8}$ & $\mathbf{9}$ & $\mathbf{1 0}$ \\
\hline F1 & - & - & - & - & - & - & - & - & - & - \\
F2 & - & - & - & - & - & - & - & - & - & - \\
F3 & - & - & - & - & - & - & - & - & - & - \\
\hline
\end{tabular}

Keterangan: $(+)=$ Menimbulkan iritasi

$(-)=$ Tidak menimbulkan iritasi

Berdasarkan hasil pengujian iritasi menghasilkan penambahan ekstrak daun pinus dengan berbagai konsentrasi tidak menimbulkan iritasi kulit pada 10 panelis. Hasil tersebut menyatakan bahwa sediaan sabun padat ekstrak daun pinus yang dihasilkan ini tidak menimbulkan iritasi sehingga aman untuk digunakan.

\section{SIMPULAN}

Berdasarkan perlakuan pada penelitian ini dapat dinyatakan kesimpulan bahwa jenis pelarut mempengaruhi efektivitas antibakteri ekstrak daun pinus terhadap $S$. aureus. Ekstrak dengan pelarut air merupakan ekstrak dengan daya hambat tertinggi yaitu sebesar $19.39 \pm$ $1.92 \mathrm{~mm}$. karakteristik dari sabun padat yang ditambahkan ekstrak dari jenis pelarut air dengan 3 perlakuan jumlah ekstrak menghasilkan sabun padat yang berwarna kuning kehijauan hingga berwarna coklat tua, memiliki aroma khas sabun dengan $\mathrm{pH}$ berkisar 10-11, stabilitas busa sekitar 57.33 - 66\%, tidak menimbulkan iritasi serta panelis lebih menyukai sabun padat dengan penambahan 1 gram ekstrak daun pinus.

\section{DAFTAR PUSTAKA}

Ambaro, F. Y., Darusman, F., \& Dewi, M. L. (2020). Prosedur Ekstraksi Maserasi Daun Bidara Arab (Ziziphus spina- christi L.) Menggunakan Pelarut Etanol dan Air. Prosiding Farmasi "Seminar Penelitian Sivitas Akademika Unisba," 6(2), 890-893. https://doi.org/dx.doi.org/10.29313/.v6i2.24050

Cahyaningrum, P. L., Yuliari, S. A. M., \& Mediastari, A. . P. A. (2020). Efektivitas Antibakteri Sediaan Sabun Padat Bunga Gemitir (Tagetes erecta L) Terhadap Staphylococcus aureus dan Escherichia coli. The Journal of Muhammadiyah Medical Laboratory Technologist, 3(2), 11-24.

Cahyanti, L. D., Sumarni, T., \& Widaryanto, E. (2015). Potensi Alelopat Daun Pinus (Pinus spp.) Sebagai Bioherbisida Pra Tumbuh pada Gulma Krokot (Portulaca oleracea). Gontor AGROTECH Science Journal, 1(2), 21-31. https://doi.org/10.21111/agrotech.v1i2.262 
Davis, \& Stout. (1971). Disc Plate Method of Microbiological Antibiotic Essay. Journal of Microbiology, 22(4).

Dewi, B., Fauzia, D. W., \& Putri, B. R. (2021). Formulasi Sediaan Sabun Padat dari Minyak Atsiri Sereh Wangi (Cymbopogon nardus L). Jurnal IImiah Pharmacy, 8(1), 65-72.

Diyantika, D., Mufida, D. C., \& Misnawi. (2017). Perubahan Morfologi Staphylococcus aureus Akibat Paparan Ekstrak Etanol Biji Kakao (Theobromo cacao) secara In Vitro. Journal of Agromedicine and Medical Sciences, 3(1), 25-33.

Fatimah, \& Jamilah. (2018). Pembuatan Sabun Padat Madu dengan Penambahan Ekstrak Kunyit (Curcuma domestica). Jurnal Teknologi Agro-Industri, 5(2), 90-100.

Fitriyanti, Abdurrazaq, \& Nazarudin, M. (2019). Uji Efektivitas Aantibakteri Ekstrak Etil Asetat Bawang Dayak (Eleutherine palmifolia Merr) Terhadap Staphylococcus aureus dengan Metode Sumuran. Jurnal IImiah Manuntung, 5(2), 174-182.

Harbone, J. B. (1987). Metode Fitokimia: Penuntun Cara Modern Menganalisis Tumbuhan. (Alih bahasa Kosasih Padmawinata, Ed.). Bandung: Penerbit ITB.

Lateka, J. A., Manurung, T., \& Prang, J. D. (2019). Analisis Faktor-Faktor yang Mempengaruhi Produksi Getah Pinus di Kabupaten Poso. D'Cartesian: Jurnal Matematika Dan Aplikasi, 8(2), 127-133.

Lutpiatina, L. (2017). Cemaran Staphylococcus aureus dan Pseudomonas aerogenosa pada Steteskop di Rumah Sakit. Jurnal Teknologi Labo, 6(2), 61-66.

Mardiana, U., \& Solehah, V. F. (2020). Pembuatan Sabun Berbahan Dasar Minyak Jelantah dengan Penambahan Gel Lidah Buaya sebagai Antiseptik Alami. Jurnal Kesehatan Bakti Tunas Husada: Jurnal IImu IImu Keperawatan, Analis Kesehatan Dan Farmasi, 20(2), 252-260.

Neis, F. A., Costa, F. de, Jr, A. T. D. A., Fett, J. P., \& Fett-neto, A. G. (2018). Multiple Industrial Uses of Non-Wood Pine Products. Industrial Crops \& Products, 130(2019), 248-258. https://doi.org/10.1016/j.indcrop.2018.12.088

Ningsih, D. R., Purwati, P., Zusfahair, Z., \& Nurdin, A. (2019). Hand Sanitizer Ekstrak Metanol Daun Mangga Arumanis (Mangifera indica L.). ALCHEMY Jurnal Penelitian Kimia, 15(1), 10-23. https://doi.org/10.20961/alchemy.15.1.21458.10-23

Putri, A. R., Sulistyowati, E., \& Harismah, K. (2019). Uji Antibakteri Daun Stevia dalam Formulasi Sabun Padat Jeruk Nipis. Seminar Nasional Edusaintek FMIPA UNIMUS 2019, 673-680.

Ramadhani, F., Girsang, E., \& Florenly. (2021). The Bioactive of Pinus Merkusii Needle and Bark Extract as Antioxidant and Antiaging. JKPK (Jurnal Kimia Dan Pendidikan Kimia), 6(1), 78-88.

Setiawati, I., \& Ariani, A. (2020). Kajian pH dan Kadar Air dalam SNI Sabun Mandi Padat di Jabedebog. In Prosiding PPIS 2020 (pp. 293-300).

Siregar, B. H., \& Nugroho, A. (2020). Potensi Ekstrak Daun Pinus (Pinus merkusii) Sebagai Bioherbisida Terhadap Gulma Teki (Cyperus rotundus L.). Jurnal Produksi Tanaman, 8(4), 363-369.

SNI. (2016). SNI 3532:2016: Sabun Mandi Padat. Jakarta.

Sukawaty, Y., Warnida, H., \& Artha, A. V. (2016). Formulasi Sediaan Sabun Mandi Padat Ekstrak Etanol Umbi Bawang Tiwai (Eleutherine bulbosa (Mill.) Urb.). Media Farmasi: Jurnal IImu Farmasi, 13(1), 14-22. https://doi.org/10.12928/mf.v13i1.5739

Sumitriasih, N. L., Ridhay, A., \& Indriani. (2019). Uji Aktivitas Antibakteri Ekstrak n-Heksan, Etil Asetat dan Etanol Kulit Batang Kayu Eboni (Diospyros celebica Bakh.) Menggunakan Metode Difusi. KOVALEN, 5(3), 233-239.

Verdiana, M., Widarta, I. W. R., \& Permana, I. D. G. M. (2018). Pengaruh Jenis Pelarut pada Ekstraksi Menggunakan Gelombang Ultrasonik terhadap Aktivitas Antioksidan Ekstrak Kulit Buah Lemon (Citrus limon (Linn.) Burm F.). Jurnal IImu Dan Teknologi Pangan (ITEPA), 7(4), 213. https://doi.org/10.24843/itepa.2018.v07.i04.p08 